\title{
Internationalization development of tertiary education system in the Republic of Croatia
}

\author{
Kristina Ferara \\ University of Zagreb Faculty of Agriculture \\ Executive MBA Training in Agribusiness and Commerce
}

This paper forms a part of Executive MBA Training in Agribusiness and Commerce which has been supported, developed and carried out in frame of the Tempus project AHEAD, CD JEP 19009-2004. Understanding of business and management with all components related (from economic principles, marketing, accounting to organisational behaviour, strategic development and thinking etc.) and especially international focus on all this areas initiated the idea of this paper.

Clear idea of strategic management from formulation, implementation and evaluation, as well as how important analyses are to develop any kind of good business or development plan (as one of the learning outcomes on MBA training) are present throughout the whole paper. Introduction to internationalization development of tertiary education system is given thru PEST analysis followed by analysis of whole tertiary education in Croatia, identifying major issues for internationalization of tertiary education, analysing them and suggesting solutions to develop it in right direction.

Croatia is about to become a member of the European Union and the level of education in Croatia is below the international average in many respects. The percentage of the total population that is both tertiary graduates $(11.9 \%)$ and 4-year secondary school graduates $(15 \%)$ is not sufficient to meet the challenges of a knowledge-based society.

As for many modern societies with low birth-rates and rising longevity, a demographic, economic and social timebomb is ticking. The transitional years brought about the restructuring of many older companies by cutting the workforce. This job cut was not compensated for by new jobs at newly created or expanding enterprises. Despite some reductions in the last few years, the registered unemployment rate in Croatia remains rather high.

This knowledge-based society that is being built has already overcome national level and in order to be recognised and competitive on global market Croatia needs to put additional effort for developing tertiary education on the principles of quality assurance, comparable study programmes, and easily readable and comparable degrees or as it is named is this paper "Internationalization at home"

In the early nineties Croatia opted for a binary system separating polytechnics from universities. Despite many problems decision to have a binary system remained. In August 2003 a new Act of Scientific Activity and Higher
Education has been adopted, and it has brought a lot of changes in tertiary education: new tertiary education structure (according to Bologna principles); support to both the specialist education offered in Polytechnics, independent Schools of Professional HE and Universities on one hand, and the academic education which is conducted solely in the Universities on the other. One intention behind the new Law has been also to strengthen the university position as against that of Faculties, and it is hoped to secure full legal integration of the universities by 2007. Under the new Law the composition of the NCHE is revised and it is given terms of reference which include proposing a coherent strategic plan for public HEIs in Croatia. It has also foreseen establishment of new Agency for Science and Higher Education.

At present the Republic of Croatia has seven universities or including universities themselves, there are $111 \mathrm{HEIs}$ in Croatia accredited by National Council for Higher Education, assisted by the Agency for Science and Higher Education. There is the very heavy concentration of tertiary education institutions (which are: universities, polytechnics, schools of professional higher education together with all its constituents) in the capital city, Zagreb, and of university resources, personnel and students at the University of Zagreb. All tertiary institutions, public and private, enrolled 132952 students for the academic year 2005/06.

The basic principles and guidelines of tertiary education policy are determined by the Croatian Parliament, which regulates them through laws, legal enactments and provisions and the system of tertiary education and science is under the responsibility of the Ministry of Science, Education and Sport. The current legal framework consists of the Act on Scientific Activity and Higher Education. The main responsibility for the development and quality of the entire scientific arena, as well as the entire tertiary education system, is assumed by the NCS and the NCHE.

National goals and targets in tertiary education are defined in Development Plan 2005-2010 and in Development Strategy for the Republic of Croatia in the 21st Century - Science. But unfortunately, in those documents clear internationalization development can not be found. This paper emphasise two major issues for internationalization of tertiary education system: assuring and improving the quality of tertiary education in order to be transparent and credible internationally and internalization at home. 
Before the new Act on Scientific Activity and Higher Education the adopted quality assurance system had been in many aspects inadequate and inefficient from the lack of appropriate legislation, quality indicators, internal quality measures, time consuming procedures, unfamiliarity of concept to academic community, non existing awareness of universities, underdeveloped quality culture, lack of experience and tradition in evaluations to misunderstood goals of evaluation and resistance of the higher education staff. Some changes are seen but not many of these assumptions are still valid and in order to develop QA system in Croatia following issues need to be addressed:

- Creating a sustainable and efficient model of quality assurance.

- Roles and responsibilities of the various bodies and organisations in relation to QA in HE should be very clear and unanimous and it must be clear that the primary responsibility for the quality of higher education programmes lies with the higher education institutions themselves.

Recommendation: There should be a national body (or ASHE can take over), at arms length from government, with the remit to establish clear processes and methodologies for periodic review of programmes, departments and units within all institutions. This body will not assess quality; but it will audit the thoroughness and appropriateness of the evaluation of quality, and prepare a framework for periodic assessment.

- As to external QA, the exact roles and the boundaries of responsibilities of NCHE and ASHE should be clarified. This could also be done, of course, in the framework of an overall exercise reconsidering the existing national scheme for QA.

Recommendation: ASHE should be responsible for accrediting institutions, not programmes. Its primary role should be to ensure that both new and existing universities and polytechnics have the mission, mandate, relevance and quality required to ensure success and integration of both the national system and regional institutions. Accreditation of institutions will also facilitate functional integration.

- HEIs should have the necessary resources, both financial and human, and enjoy an appropriate degree of autonomy in order to be able to develop and operate their internal QA systems. They should nevertheless, not forget that autonomy means responsibility and accountability at the same time.

- The external QA system should, in accordance with the European Standards and Guidelines (ESG), be transparent and clear to all. If it involves accreditation in the future too, then when revising the predefined criteria, the involvement of a broad spectrum of experts from HEIs (including private institutions and students as well) could be considered in the drafting process.

- An impact analysis of the performed programme accreditation of the new, Bologna type degree programmes could be carried out. Results of this could be fed into the possible refinement procedures of the national QA system.

- A clear conceptual separation should be made between accreditation and the decision on licensing HEIs and degree programmes to operate.

- Any possible refinement of the current QA arrangements or the establishment of a future national scheme of external QA in Croatia should be accomplished based on a holistic approach, on the system level.

- Quality assurance is perceived differently from different stakeholders. It is often seen as a control mechanism for higher education institutions. It should be made clear, that in line with the European Standards and Guidelines it should be (primarily) based on the internal mechanisms in HEIs, and then linked to other, higher levels which provide external mechanisms.

- An important part of the quality assurance is quality of teaching and learning and, including learning outcomes, assessment (examinations) of students and quality of teaching. These are issues that haven't been addressed yet in proportion to their importance and should be addressed.

- MOZVAG system that served for accreditation of study programmes, and that could serve as information system on quality assurance on all levels providing data needed both for HEIs, universities, ASHE and NCHE, as well as the Ministry. System itself should also provide for link with the existing MIS that exist in different HEIs, especially ISVU, which is used by more that half of HEIs.

- Quality assurance in HE should be built both on experience from the European Higher Education Area as well as on the experience and expertise which has been developing in the country in last decade.

- Creating a culture of assessment and accountability in Croatian tertiary education is a long-term, stepped process requiring vision, leadership and commitment over time.

From all this mentioned above it is clear that Croatia needs to built a quality assurance system. Maybe the best solution would be to built together with all stakeholders (MZOS, NCHE; NCS, representatives from tertiary education institutions, students, employers) "National model for quality assurance" which will clearly define responsibilities between various bodies and institutions, objectives, targets, methods, criteria and consequences in line with ESG.

Internationalization is seen as a major vehicle for the achievement of a higher quality of tertiary education and its competitiveness. The main opportunity for the internationalization of tertiary education institutions has been through EU projects that Croatia has had access to (TEMPUS, Jean Monnet, Marie Curie), as well as through direct bilateral and multilateral cooperation with institutions abroad. Unfortunately, the national policy did not provide special measures to ensure the sustainability of joint programs 
developed through the Tempus projects. No mention was made of the infrastructure that would support them, or grants for the domestic students who do not have the financial resources to cover the costs of international programs.

The mobility of students and teachers, both nationally and internationally, is at an unacceptably low level of development. There are a number of obstacles inside the national legal and administrative system, but external problems exist because Croatia was not eligible to join European Union mobility programs. The main instrument for the student and academic mobility are bilateral and multilateral interuniversity agreements of cooperation in different fields. Possibilities are limited to only a few programs such as Tempus JEP (Joint European Projects) and Tempus IMG (Individual Mobility Grants), CEEPUS, DAAD, and Fulbright. In 2009 Croatia will apply for participation in EU LLP.

The major weakness of the system from the perspective of the academic community is recognized as the lack of general strategy in the sector. But some steps of internationalization are mentioned in the Ministry of Science, Education and Sports Education Sector Develop- ment Plan 2005-2010 (establishment of system of easily recognisable and comparable academic and professional degrees and international recognition; encouragement of mobility of students and teachers).

In order to develop internationalization at home bilateral and multilateral interuniversity agreements should be encouraged and special financial incentives given to increase the so far still modest numbers of Croatian exchange students.

Courses in foreign languages (notably in English) should be offered in order to increase the number of incoming foreign students. Croatian tertiary education institutions should open themselves to all forms of programme and institution mobility. Mobility, both national and international, as well as fruitful international cooperation must be rewarded and made individually worthwhile.

Further implementation of the Bologna Process is an important step towards growing internationalisation of the Croatian system of tertiary education.

The most important goal in order to develop internationalization at home should be creation of general internationalization strategy. 
